\title{
La Republica Española en el exilio y la alternativa monárquica a Franco desde el final de la II Guerra Mundial hasta la resolución de las Naciones Unidas de noviembre de 1950
}

\author{
Miguel Ángel Yuste de Paz \\ (UNED)
}

The Spanish Republic in exile and the monarchical alternative to Franco from the end of the II World War to the United Nations resolution of november 1950

\section{RESUMEN}

Las «instituciones republicanas» mantuvieron la continuidad del régimen derrotado en el exilio. Su desunión y el orden internacional que dio lugar a la guerra fría tras la II Guerra mundial determinaron su fracaso. El régimen de Franco se constituyó en reino con la Ley de Sucesión a la Jefatura del Estado, de 26 de julio de 1947.

Así, durante la dictadura de Franco existieron virtualmente un reino sin rey en España, que duró hasta la desaparición del dictador, y una República en el exilio sin territorio donde ejercer, ni legitimidad democrática que hacer valer.

Un importante sector de la oposición republicana a Franco trató de llegar a un pacto con los monárquicos para un plan de transición que quedó herido de muerte en 1948 cuando el 25 de agosto Don Juan se entrevistó con Franco en el yate «Azor».

PALABRAS CLAVE: Exilio. Desunión republicana. Guerra fría. Monarquía virtual. Consolidación de la dictadura. Plan de transición. Fracaso.

\section{ABSTRACT}

The Spanish republican institutions in exile tried to keep the defeated regime out of Spain up. His lack of unity and the international new order after the Second World War that originated the Cold War were the reasons of the failure. In July $26 t$ 1947, the Franco regime was itself constituted into kingdom with the Chief of State Succession Law.

So, during the Franco dictatorial regime existed both, a kingdom with a king to be only after dictator's death, and a Republic in the exile without territory nor democratic legitimacy to present.

An important sector of the republican opposition to Franco tried to reach an agreement with the monarchist organisations forces for a transition plan. But the meeting between Franco and Don Juan in the yacht "Azor» in 25th of august 1948 meant the dead end of the agreement.

KEYWORDS:

Exile. Lack of unity. Cold War. Monarchy on paper. Franco regime consolidation.

Plan for transition. Failure. 
Las «instituciones republicanas» ${ }^{1}$ en el exilio trataron de mantener fuera de España la continuidad de la República derrotada en la guerra civil. Su mayor actividad se registró entre el final de la II Guerra Mundial, cuando pareció que la derrota del fascismo y el nazismo acarrearía la desaparición del régimen de Franco, y al menos hasta 1947.

El régimen dictatorial que tomó el poder después de la guerra civil consecuencia de la rebelión contra la República el 18 de julio de 1936, fue poco a poco reconocido internacionalmente. Para transmitir el mensaje de que el régimen de Franco evolucionaba en un sentido más acorde a la nueva sociedad internacional salida del final de la segunda guerra mundial, el nuevo Estado se constituyó en reino con la Ley de Sucesión a la Jefatura del Estado, de 26 de julio de 1947, aunque no fue hasta el 22 de julio de 1969 cuando las Cortes aprobaron la designación del príncipe Juan Carlos como sucesor.

Así que, dentro del largo período histórico de la dictadura de Franco, coexistieron virtualmente un reino sin rey en España, que duró hasta la desaparición física del dictador, cuando se produjo la restauración, ahora sí, de una monarquía que adoptó más tarde el adjetivo de parlamentaria, y una República en el exilio sin territorio donde ejercer, ni legitimidad democrática que hacer valer, cuyo gobierno se extinguió el 21 de junio de 1977.

\section{LA CONTINUIDAD DE LA REPÚBLICA FUERA DE ESPAÑA}

El mantenimiento de las instituciones republicanas en el exilio no podía ser una mera transposición fuera de España de sus competencias. Las especiales condiciones que vivían entonces sus componentes y la excepcional situación histórica eran factores que contribuyeron a acentuar las divisiones del bando republicano, preexistentes desde la guerra civil. De hecho, poco antes del final de la guerra, la Diputación Permanente de las Cortes, sin escuchar la petición del presidente de la República, Diego Martínez Barrio, para que ratificase la legalidad del gobierno de Juan Negrín, resolvió reconocerse como la única institución representativa de la República. $^{2}$

Muchos se preguntaban en qué se basaba la legitimidad republicana si las instituciones estaban fuera de España, Negrín les contestaba:

1 Al utilizar el término Instituciones que figura también en el título de esta tesis doctoral y que normalmente aparece junto al adjetivo republicanas, hago referencia fundamentalmente a los órganos políticos constitucionales que como un espejismo de legalidad continuaron desarrollando su labor fuera del territorio español. Las instituciones incluyen: La Presidencia de la República, el Gobierno de la República, las Cortes, la Diputación Permanente, los distintos Ministerios, los Gobierno autónomos, etc. Cuando hago referencia a partidos políticos, sindicatos, Juntas u organizaciones de enlace o unión, etc., me referiré a ellos con el nombre genérico de organizaciones políticas, siempre que no lo haga con su respectivo nombre o sigla.

2 J. M. DEL VAlLE, Las Instituciones de la República español en exilio, Ruedo Ibérico, París, 1976, p. 18. 
Yo reconozco que hasta bien entrado el año 1940 hemos hecho en ocasiones el más completo y profundo de los ridículos. Lo sabíamos por anticipado, (...). Nosotros hemos tenido un gran argumento en favor de esa posición. Éste ha sido la legalidad; argumento irrecusable, porque aunque se nos adujera que quizá la opinión del pueblo español había cambiado, nosotros podemos responder que hasta tanto que el pueblo español libremente no lo expresara así, nosotros teníamos la obligación de considerarnos su legítimo representante ${ }^{3}$.

La inercia tras la guerra era poderosa, y tampoco se habían creado plataformas de oposición capaces de sustituir a los restos institucionales de la República. Pero mientras, había que gestionar los bienes estatales salvados, ayudar a las miles de exiliados y sufragar la actividad opositora a Franco, además de conseguir el respaldo de los organismos internacionales. En todo caso, el gobierno del exilio no podía actuar ya como el gobierno de España.

El 10 de agosto de 1942, la Diputación Permanente de las Cortes proclamaba que: «El Parlamento español legítimo podrá ser reunido en algún lugar de tierra libre, en sesión plenaria...». ${ }^{4}$ El Presidente de las Cortes republicanas, Diego Martínez Barrio, logró la autorización del gobierno de México para reunirlas. Muchos pensaron que aquella convocatoria no era oportuna y que, además, entorpecería la labor de la Junta Española de Liberación (JEL), ${ }^{5}$ justo cuando comenzaba a obtener resultados alentadores.

Con la reunión de las Cortes, el exilio republicano trataba de mostrar su continuidad histórica. Desde la rebelión del 18 de julio de 1936, 127 diputados habían fallecido como consecuencia directa o indirecta de la guerra y la represión posterior. El 10 de enero de 1945 asistieron 72 diputados y se adhirieron 49 desde otros países. Como no se llegaba al mínimo exigido de 100 votos nominales, el grupo socialista liderado por Prieto adujo falta de quórum. Las minorías lo apoyaron y la reunión se suspendió.

El 17 de agosto se reunían por segunda vez, ahora en el Palacio de gobierno de la Ciudad de México, 96 de los diputados. ${ }^{6}$ Allí, Martínez Barrio prometió el cargo de presidente de la República española. Ese mismo día, fiel a su compromiso, Negrín presentó su dimisión. Martínez Barrio encargó a José Giral, de Izquierda Republicana, la formación de un gobierno integrador. La creación del nuevo go-

\footnotetext{
3 Discurso de Juan Negrín en el Palacio de Bellas Artes de México, 1 de agosto de 1945, Documentos Políticos para la historia de la República española, I, Colección Málaga, México, 1945, p. 35.

4 J. M. DEL VALLE, op. cit., pp. 62-63.

5 Por otro lado, el 20 de noviembre de 1943, se creo en México la Junta Española de Liberación (J.E.L.), que se basaba en el acatamiento de la Constitución de 1931, pero también en los principios de la Carta del Atlántico, dada a conocer por Churchill y Roosevelt el 14 de agosto de 1941. Su presidente fue Diego Martínez Barrio.

6 A la reunión asistieron representantes diplomáticos de Francia, Unión Soviética, Suecia, Checoslovaquia, Colombia, Ecuador, Nicaragua, Perú, Uruguay y Venezuela, en Sonsoles CABEZAS SÁNCHEZ-ALBORNOZ, Historia política de la Il República en el exilio, Fundación Universitaria Española, Madrid, 1997, p. 42.
} 
bierno provocó la autodisolución de la JEL el 31 de agosto de 1945, creyendo que así ayudaría a que aquel fuese reconocido por un mayor número de miembros de la Naciones Unidas.

De una forma $u$ otra, las instituciones republicanas trataban de mantener una apariencia de normalidad. El 7, 8 y 9 de noviembre se reunieron de nuevo las Cortes en la Ciudad de México. Allí Giral presentó su gobierno a los 135 diputados presentes. El nuevo ejecutivo se convirtió en un nuevo motivo de controversia. Un informe del ministro cenetista José Expósito Leiva de febrero de 1946 es bastante ilustrativo de la situación existente:

Indalecio Prieto estima que el cambio de régimen, pasando sin transición del franquismo a la República, es un absurdo. Largo Caballero cree, como Prieto, que un gobierno de concentración que abarque a todos los antifranquistas es la mejor solución. Caballero agrega que ha mantenido conversaciones con los socialistas franceses, Leon Blum y Vicent Auriol, los cuales mantienen el mismo criterio.

Miguel Maura es partidario de un plebiscito dirigido por un gobierno de concentración popular, que abarque desde los monárquicos a la CNT, con exclusión de los comunistas.

La Pasionaria propicia un gobierno de coalición nacional, en el que estén incluidos los Monárquicos. Negrín y sus amigos (Álvarez del Vayo, González Peña, Angel Galarza, etc.) no creen tampoco que la solución republicana, sin transición sea posible. Portela Valladares es también partidario del plebiscito a priori y de las soluciones extragubernamentales.

Por su parte, Trifón Gómez, ministro en el gobierno Giral, estima que «el gobierno es el mayor obstáculo para encontrar una fórmula que resuelva honrosamente el problema de España?

A principios de 1946, los norteamericanos daban pocas posibilidades a Giral:

(...) Los representantes diplomáticos de los tres países en Madrid podrían demandar un encuentro con el ministro de Exteriores y el jefe del Ejército español. (...) les harían saber que nuestros tres gobiernos sentían que había llegado el momento, (...) para que el régimen de Franco de un paso y desaparezca del panorama español.

(...) Antes de llevar a cabo alguna acción que conlleve la ruptura de relaciones con el presente régimen en España, los gobiernos de Estados Unidos, Gran Bretaña y Francia deben acordar sus futuras relaciones con el régimen de Giral.(...) Los componentes del grupo de Giral son (...) estimables y españoles excepcionales, (...); sin embargo, tienen pocos seguidores en el interior de España ${ }^{8}$.

El 17 de diciembre, en un discurso en Ciudad de México, Prieto desmontaba sin reparos las expectativas del gobierno Giral ${ }^{9}$ :

\footnotetext{
7 Fidel Miró, Y España ¿ cuándo?, Libro Mex, México, 1959. Citado en JosÉ BorRás, op. cit., pp. 42-43.

8 Informe de la División de asuntos europeos del Departamento de Estado USA, John Hickerson, para su jefe, Culbertson, NA 852.00/1-1146, 59, 6336.

9 Podemos leer acerca del discurso de I. Prieto, en J. M. DEL VAlLe, op, cit, pp. 224 y 225; y JaVIER TUSELL, op. cit., pp. 170-171.
} 
¿Que posibilidades tiene el gobierno que preside el señor Giral de establecerse en España? Mi respuesta es netamente negativa: ninguna. $Y$ no es que lo crea yo solo, sino que este convencimiento lo tiene el mismo gobierno, (...).

(...).El gobierno es un barco inútil que no llegará jamás a puerto y que, navegando a la deriva, puede constituir un obstáculo para la navegación. Por consecuencia, nuestro deber es no solamente cortar las amarras, sino hundir el barco. ¿Lo oís bien? Hundir, para bien de todos, instituciones inútiles y perniciosas.

El día 22, tras exponer un voluntarioso programa político en el que fue el último Consejo de Ministros de su gobierno, los ministros socialistas y anarcosindicalistas dimitieron, y a Giral no le quedó más remedio que presentar la dimisión. Se quebraba la línea de legitimidad que había amparado la formación del gobierno republicano en México, heredero directo de la Constitución de 1931. La crisis de gobierno abrió el debate sobre si seguía siendo conveniente mantener un gobierno republicano en el exilio. Mientras que Martínez Barrio buscaba a alguien capaz de formar uno nuevo, incluyendo a Negrín, que junto a Del Vayo trataban de convencer al presidente de la República de la valía de su alternativa, Prieto y Trifón Gómez consideraban que cualquier gobierno que se crease fuera de España sería un gobierno fantasma como el de Giral había sido. Creían más importante colaborar en el interior de España para alcanzar un acuerdo entre todos los antifranquistas. ${ }^{10}$ En esto coincidían con los monárquicos del interior, que creían que su acuerdo con la Alianza Nacional de Fuerzas Democráticas, (ANFD), constituida a finales de 1943 en el interior, estaría pronto listo. ${ }^{11}$

Tras varios intentos fallidos, incluido Giral, Martínez Barrio encargó la formación de gobierno a Rodolfo Llopis, que trató de integrar al mayor número posible de fuerzas políticas y sociales, teniendo muy en cuenta a las del interior de España. Esto puede dar la impresión de un proceso institucional cuasi normal, el comunista Manuel Azcárate pone las cosas en su sitio:

Es curioso hasta que punto se apoderó de todos nosotros una especie de "cretinismo parlamentario». La «crisis de gobierno». Cuando Llopis sustituyó a Giral como presidente, fue una ceremonia kafkiana: desfilaban las direcciones de los partidos por un despacho - atribuido al presidente de la República- en que éste realizaba «sus consultas» sobre el futuro gobierno. Todo eso como si fuesen de verdad, y no una farsa que no influía sobre nada, ni sobre España, ni sobre las cancillerías que tenían capacidad para cambiar la situación española ${ }^{12}$.

\footnotetext{
${ }^{10}$ Embajada USA en París para el Secretario de Estado, NA852.00/1-2947, 59, 6339.

11 Encargado negocios USA en Madrid para el Secretario de Estado, FRUS, 1947, Vol. III, 852.00/2447.

12 Manuel Azcárate, Derrotas y Esperanzas, La República, la Guerra Civil y la Resistencia, Tusquets, Barcelona, 1994, p. 304.
} 


\section{NECESIDAD OBLIGA}

Los contactos entre monárquicos y republicanos se habían incrementado desde 1946, sobre todo dentro de España. En diciembre, un representante de la CNT había llegado a un acuerdo con $\mathrm{D}$. Juan al que se iba a adherir el gobierno republicano, pero la central anarquista lo desautorizó y el acuerdo se deshizo. ${ }^{13} \mathrm{~A}$ finales de enero de 1947, Martínez Barrio había enviado un intermediario a entrevistarse con el general Juan Beigbeder -Aranda había sido enviado a Baleares por Franco- para negociar la formación de un gobierno provisional. Como Beigbeder no tenía autorización de D. Juan, habían enviado a Lisboa a un representante para entrevistarse con Gil Robles y Sainz Rodríguez y acordar un encuentro entre dos representantes de Martínez Barrio, dos del Pretendiente, dos de la ANFD, y dos generales en representación del Ejército. El objetivo era formar un gobierno que pudiese ser reconocido por Naciones Unidas. Desde enero a marzo la iniciativa fue de los generales Aranda y Beigbeder, que llegaron a un entendimiento con la ANFD, aunque ahora fue el grupo cercano a $D$. Juan a quien no gustó y lo invalidó. En mayo, la iniciativa vino de la izquierda para atar un acuerdo entre la ANFD y D. Juan, pero también sin fruto. ${ }^{14}$

El gobierno Llopis se vio pronto cuestionado desde su propio partido. Prieto convirtió la asamblea de delegados socialistas de julio de 1947 en un Congreso de gran trascendencia del que el presidente salió tocado, lo que aceleró la caída de su gobierno. Prieto había dicho que:

El Partido Socialista Español en el exilio, (...), no se opondrá a ninguna fórmula que, por caminos diferentes de los que la Constitución trace al gobierno, pudiera conducir a la liberación de España y la restauración de la república sin efusión de sangre ${ }^{15}$.

La caída del gobierno Llopis fue otro capítulo del fracaso de las instituciones republicanas. En septiembre de 1947, una comisión del partido socialista reunida en Toulouse decidió promover la aceptación de las recomendaciones de la ONU de diciembre de 1946 entre todas las fuerzas políticas y sindicales antifranquistas. Los socialistas tenían claro lo que deseaban, pero también lo que podían ofrecer:

Si el Partido socialista español sacrifica, con gran pesar, la incuestionable legitimidad de las instituciones republicanas, aquellos que están en frente de nosotros deben también poner a un lado sus propias supuestas legitimidades. Entonces sería posible para nosotros alcanzar un acuerdo ${ }^{16}$.

\footnotetext{
${ }_{13}$ Un informe confidencial de la Delegación francesa en España menciona el proyecto de acuerdo al que llegaron Don Juan y Vicente Santamaría en Lisboa, así como los problemas de éste para verlo aceptado por la ANFD y la propia CNT, en: AD/MAE, Z, 40, 22-11-46.

14 Informe del Foreign Office, Spanish Opposition, FO371-67876, Z4980, 20-5-47.

15 Acuerdos de la Asamblea socialista: J. MiRAvitLles, Cartas de Nueva York, ARE 95.1., 1.12.4., 288-47.

16 Carta firmada por Luis Jiménez de Asúa, Trifón Gómez e Indalecio Prieto al Foreign Office, F0371-67873, 11-9-47.
} 
Si era difícil que los republicanos aceptaran estas renuncias, más difícil era lograrlo de los monárquicos que, no lo olvidemos, estaban entre los vencedores de la guerra civil. La estrategia de «transición y plebiscito» ${ }^{17}$ formulada por Prieto, a cuya formulación contribuyó el histórico socialista Francisco Largo Caballero, no hacía cuestión fundamental del restablecimiento de la República. Convencido de la inminente restauración monárquica aupada por las potencias anglosajonas, Prieto trato de convencer a los republicanos de la necesidad de un pacto, como da fe su artículo O Plebiscito o Monarquía, que se había publicado en febrero de $1947 .{ }^{18}$

Si rechazamos el plebiscito, la monarquía advendrá fatalmente». «...cuanto iríamos a perder lo tenemos perdido de antemano. Colocados en el punto de vista de los intransigentes más tenaces, perderíamos, a lo sumo, una legitimidad, perfecta desde puntos de vista jurídicos, pero inefectiva. Otra vez he dicho, que cuando se aduce a toda hora la legitimidad, descúbrese que ésta carece de efectividad.

El Foreign Office ya pensaba que Prieto podía jugar un papel determinante para organizar un gobierno moderado que reemplazase a Franco, ${ }^{19}$ y sabía que $D$. Juan compartía esa opinión. ${ }^{20}$ Los británicos no veían con malos ojos un régimen monárquico si era fruto de un pacto, aunque también creían que era peligroso asumir la restauración de la monarquía como la única alternativa posible a Franco, ya que inmediatamente habría que plantearse dos cuestiones: «¿Qué monarca? ¿Sería Don Juan un monarca constitucional satisfactorio?»21

El 26 de septiembre de 1947, Prieto se entrevistó en Londres con el ministro de exteriores, Ernest Bevin. Prieto, que decía no haber tenido negociaciones directas con los líderes monárquicos hasta ese momento, creía que desde Lisboa se resistían a la coalición a la espera de un golpe militar que llevara a D. Juan al poder, confiando en tener el reconocimiento posterior de Estados Unidos y Gran Bretaña. Bevin rechazó esta posibilidad y propuso a Prieto que se encontrara con Gil Robles en Londres. ${ }^{22}$ Prieto le pidió que intercediera ante los monárquicos para convencerles de las ventajas de llegar a un entendimiento ${ }^{23}$.

Tras la entrevista, Bevin concluyó que Franco solamente podría ser sustituido por una personalidad como D. Juan, pues si el poder recaía en una Junta, o algo parecido, existía un claro riesgo de reanudación de la guerra civil. ${ }^{24}$ Esta opinión era compartida por D. Juan, para quien el Ejército no consentiría la cesión del po-

17 Ya antes del final de la guerra civil habló de una solución plebiscitaria en un discurso en el «Luna Park» de Buenos Aires, Sobre los orígenes de la estrategia de transición y plebiscito: JULIO ARÓSTEGUI, Francisco Largo Caballero en el exilio. La última etapa de un líder obrero, Fundación Largo Caballero, Madrid, 1970, p. 97.

18 ARE, 616.1, 19-2-1947.

19 Carta de Ivor Thomas para Bevin, FO371-60334, Z2891, 23-3-46.

20 Victor Mallet, en Madrid, a F. O., FO371-60376, 1-3-46.

21 Minuta F. O., FO371-60335, 28-6-46.

22 Hartmut Heine, op. cit. p.389; Richard Gillespie, op. cit., p.125.

23 Documento secreto de la conversación entre Prieto y Bevin, FO371-67873, Z 8562/16/41, 29-9-47.

24 Informe secreto de la embajada USA en Londres, NA852.00/10-347, 59, 6340. 
der a un gobierno provisional que convocara un plebiscito, con el riesgo de que trajera de nuevo la República.

\section{PRIETO Y GIL ROBLES A LA BÚSQUEDA DE UN ACUERDO}

Necesidad obliga, la vieja elección entre monarquía o república buscaba ahora un terreno de entendimiento necesario para construir un mínimo escenario de libertad. Para ello, a los promotores de un acuerdo no tenían más remedio que superar las desconfianzas existentes o al menos, obviarlas provisionalmente. Indalecio Prieto y José María Gil Robles se entrevistaron cuatro veces en Londres, entre los días 15, 17 y 18 de octubre de 1947, en un piso cercano a Picadilly Circus, gracias a las facilidades del Foreign Office. Para Bevin, el acuerdo entre socialistas y monárquicos era la única solución factible que, además, evitaría a las potencias, entre ellas el Reino Unido, futuras acciones contra el régimen de Franco. ${ }^{25}$

El Foreign Office recordó a Bevin que había que dejar claro a Gil Robles que no aceptaría ninguna solución sin el acuerdo de Prieto, y que para ello debía esforzarse hasta el límite, pues sólo así la solución alcanzada sería duradera. Además, se tenía que lograr el apoyo del Ejército y de la Iglesia, y también la aprobación de los sindicatos y la izquierda en general. ${ }^{26}$ No sería fácil. El tema del plebiscito volvió a ser el punto en discordia. Los monárquicos no aceptaban la celebración de una consulta que, decían, conduciría al país al caos, y que, sin embargo, para Prieto, era esencial, aunque para poder celebrarse con garantías tuviera que ser supervisado por las tres potencias. Gil Robles aprovechó para preguntar a Bevin si, en tal caso, las potencias estaban dispuestas a enviar fuerzas. La propuesta monárquica era que $\mathrm{D}$. Juan ocupara el trono y que el régimen político fuese provisional hasta ser confirmado por un plebiscito o un referéndum constituyente. A Bevin le parecía que las dos partes daban demasiada importancia a la Nota tripartita, ya que ésta no contenía reglas, sino que reflejaba la opinión de los países firmantes sobre como llevar a cabo el proceso de cambio, pero que el método exacto lo debían realizar los partidos de oposición a Franco. ${ }^{27}$ Los puntos principales de las negociaciones se pueden leer en dos memorándums redactados por separado, el de Gil Robles destinado al gobierno británico, ${ }^{28}$ y el de Prieto para informar a su partido. ${ }^{29}$ Existían muchos puntos de acuerdo, si bien el procedimiento a seguir para la implantación de «una vida política normal» seguía siendo el principal escollo para alcanzarlo en su totalidad.

25 DAVID J. Dunthorn, Britain and the Spanish Anti-Franco Opposition, 1940-1950, Palgrave, Hampshire \& New York, 2000, p. 7.

${ }_{26}$ Informe firmado por J. N. O. Curle, F. O., sobre la entrevista entre Gil Robles y Prieto, con recomendaciones para Bevin, FO371-67908A, 16-10-47.

27 Conversación de Bevin con Gil Robles, FO371-67908A, 17-10-47.

28 Memorándum de Gil Robles para el gobierno británico, FO371-67908A, Z-9382, 18-10-47.

29 Informe para el Partido Socialista, FO371-67908A, Z-9381, 19-10-47. 
Tras los encuentros en Londres, las negociaciones prosiguieron cerca de un año con intermediarios autorizados: en sus principios, Fernando de los Ríos por los socialistas y Félix Vejarano por los monárquicos. Gil Robles propuso a Prieto una «fórmula conservadora» en forma de «gobierno-regencia» que asumiría todos los poderes. Tendría una composición moderada, con participación de la izquierda no comunista, que prepararía una consulta electoral en el plazo más breve posible, «bien un referéndum sobre un texto orgánico, o bien la convocatoria de un organismo constituyente». Prieto se sintió desconcertado ante la propuesta, y aunque no la rechazaba categóricamente, no le pareció un término aceptable por la confusión que creaba, y sobre todo, si pretendía reconocer, a priori, a la Monarquía como el régimen legal. No aceptaba el referéndum por ser un sistema desacreditado por Franco, pero se mostraba a favor de la consulta. A De los Ríos le decía:

Nos convendría a los comisionados socialistas (...) que las gestiones iniciadas (...) en Londres avanzaran (...) antes de reunirse el Congreso del PSOE en el exilio (...) el día 19 de febrero ${ }^{30},(.$.$) , porque las esperanzas de los republicanos «le-$ gitimistas", y acaso también de algunos correligionarios nuestros, cífranse en que presentándosela como fracasada la actitud del congreso que en julio último adoptamos,(...), rectificando sus acuerdos de entonces, robustezca el «legitimismo» y refuerce al Gobierno, cuyos miembros así lo esperan ${ }^{31}$.

La propuesta de «gobierno-regencia» gustaba al Foreign Office, pues evitaba el espinoso dilema de monarquía o república, aunque favorecía a la monarquía. $\mathrm{Si}$ España era ya, técnicamente, un reino sin rey, el término regencia era un apósito a la aprobada Ley de Sucesión que podía ser aceptado por los españoles, y que era una alternativa razonable al plebiscito previo de la izquierda. Los británicos estaban convencidos de que los vencedores de la guerra civil, muchos de ellos cercanos a la Monarquía, difícilmente iban a ceder el poder a los vencidos si no adquirían seguridades. ${ }^{32}$

Gil Robles contestó a Prieto proponiéndole que aprobasen el texto enviado el 15 de mayo, pero éste no lo admitió debido a las modificaciones introducidas en el preámbulo que eliminaba el término «gobierno provisional», y a la redacción del artículo $8 .^{\circ}$ en cuanto al tipo de consulta sobre el régimen político definitivo. ${ }^{33} \mathrm{El} 24$ de agosto, Indalecio Prieto envió una fórmula definitiva del preámbulo y del famoso artículo $8 .^{\circ}$ desde San Juan de Luz donde esperaba. ${ }^{34}$ Pero entonces, cuando estaba cercana la firma del acuerdo, apareció la pregunta fundamental que todo el mundo había ido demorando:

30 El Congreso fue retrasado hasta el 25 de marzo por Prieto para ganar tiempo para las negociaciones. Carta de Prieto a Gil Robles, 2-5-48, FO371-73358, Z4210, 8-5-48.

31 FO371-73358, 12/13-1-48.

32 Minuta de Horsfall Carter, Departamento de Investigación, F. O. FO371-73358, Z4210, 8-5-48.

${ }_{33}$ Cartas entre Gil Robles, (31-5-48), y Prieto, (8-6-48), FO371-73358, Z5146, 30-6-48.

34 Cartas entre los monárquicos y Prieto, 13-7/25-7/9-8/17-8/21-8/24-8/48, FO371-73359, Z7414. 
Suponiendo que Gil Robles y Prieto establezcan un acuerdo, el aspecto esencial que quedaría para resolver el problema español sería: ¿Quién va a poner el cascabel al gato? ${ }^{35}$

El cascabel parecía querer entregárselo en mano D. Juan el 25 de agosto de 1948, al entrevistarse con Franco en el yate «Azor», sorprendiendo a Prieto, a sus colaboradores, a todos los espectadores del proceso de negociación, y a medio mundo.

El general Aranda creía que Estados Unidos había empujado a Franco a entenderse con Don Juan porque temía los posibles perjuicios de un acuerdo entre monárquicos y socialistas para su política europea. ${ }^{36}$ De hecho, los norteamericanos habían tratado de convencer a los monárquicos de los beneficios de un entendimiento con el dictador. ${ }^{37}$ Cada vez más preocupados por evitar cualquier riesgo de implantación comunista, no iban a exigir a Franco la democratización de España para iniciar relaciones con él. Franco empezaba a ver como se hacía realidad su sueño de ser considerado un aliado imprescindible contra el comunismo. ${ }^{38}$

D. Juan reconoció que Franco había querido entrevistarse con él desde su llegada a Portugal, y que finalmente accedió ante la evidencia de que una nueva negativa iba a ser aprovechada por el dictador para atacarle. Algunas agencias dijeron que aquello significaba su renuncia al trono y el reconocimiento de su hijo como sucesor de Franco, lo que según el entorno del Pretendiente era falso, pues Franco sólo habló vagamente sobre la posibilidad de que D. Juan Carlos se educase en España y D. Juan lo escuchó como una posibilidad más, sin prometer ni acordar nada al respecto. ${ }^{39}$ El Pretendiente autorizó a Gil Robles a informar al Foreign Office sobre los pasos previos a la entrevista y el desarrollo de la misma: ${ }^{40}$

I. D. Juan primero recibió en Inglaterra una invitación para entrevistarse con Franco el mes pasado. Ésta vino por carta del señor Danvila, un socio del Duque de Sotomayor, jefe de la casa de D. Juan. No se envió contestación.

II. Seguidamente, Sotomayor y Danvila se presentaron a D. Juan en Arcachon con una renovada invitación. D. Juan entonces decidió aceptar creyendo que no estaba justificado negarse, al menos sin escuchar lo que Franco tenía que decir.

35 Minuta de Horsfall Carter, Departamento de Investigación, F. O., FO371-73358, Z4210, 8-5-48.

36 Entrevista de Malley, embajada británica en Madrid, con Aranda, FO371- 73363, Z7977, 28-9-48

37 En enero de 1948, Culbertson les dijo a dos consejeros de D. Juan, uno de los cuales era José M. ${ }^{a}$ de Oriol, que la caída de Franco mediante un bloqueo económico no iría en favor de los monárquicos sino de la izquierda, y les recomendó que dijeran a Don Juan que buscara algún tipo de acuerdo con Franco, en: Paul Preston, Franco, caudillo de España, Grijalbo, Barcelona, 1994, p. 718.

38 D. Juan observa tras entrevistarse con Franco: «Cree en lo inevitable de una nueva guerra, en la que considera que tiene mucho que ofrecer a las democracias», FO371-73363, Z7593, 13-9-48.

39 Nota recibida por Aranda autorizada por Don Juan, acerca de las circunstancias que rodearon el encuentro entre Franco y D. Juan y lo que trataron, adjunta a la citada minuta de la embajada británica sobre una entrevista de Malley con Aranda, FO371-73363, Z7977, 28-9-48.

40 Concepción y desarrollo de la entrevista entre Franco y D. Juan, transmitida por Gil Robles, y enviada por R. W. Parkes al Foreign Office, FO371-73363, Z7593, 13-9-48. 
III. Los resultados del encuentro fueron, brevemente, como siguen:

(a) Ninguna decisión fue alcanzada en ninguna cuestión.

(b) No hubo cambios en la política previamente declarada por D. Juan.

(c) D. Juan obtuvo la impresión de que Franco planeó el encuentro como una maniobra política en beneficio de sus propios intereses solamente.

(d) D. Juan tuvo también la fuerte impresión de que Franco estaba muy preocupado por la situación económica española

IV. Las cuestiones más importantes para Franco fueron:

(a) Se vanagloriaba de la fortaleza de su posición presente, por la que podría, cuando lo desease, restaurar a $\mathrm{D}$. Juan como un rey popular.

(b) Creía en la inevitabilidad de otra guerra, en la que él consideraba que tendría mucho que ofrecer a las democracias.

(c) Estaba convencido de que la cuestión de la restauración debía esperar hasta después de la anunciada guerra.

Los monárquicos habían buscado en las negociaciones con los socialistas estar en buenos términos con la izquierda moderada en un período en el que la presión internacional tenía visos de acabar con el dictador. Significativamente, cuando disminuyó esa presión y se alejó el riesgo de una intervención exterior, Don Juan accedió a que su hijo se educase en España. Aunque esto no significaba una abdicación en beneficio de $\mathrm{D}$. Juan Carlos, creyó que sólo desde dentro del franquismo la monarquía podía prosperar. No rompió con los socialistas, pero lo acordado con ellos no servía para el inmediato futuro. El 7 de octubre, Trifón Gómez hacía entrega en las embajadas del Reino Unido, Estados Unidos, Bélgica, Holanda y Luxemburgo en París, además de al gobierno francés, una declaración con las bases del acuerdo firmado por Indalecio Prieto, Trifón Gómez, Antonio Pérez y Luis Jiménez de Asúa, del Partido Socialista Obrero Español, y que sería conocido como «Pacto de San Juan de Luz».41 Ésta sería la única declaración que se dio a conocer, pues la que les tocaba llevar a los monárquicos a las embajadas en Madrid no se entregó. Era ciertamente desconcertante que D. Juan siguiese diciendo que los «principios políticos» ${ }^{42}$ acordados con los socialistas seguían en vigor cuando ya había accedido a que su hijo se educase en la España de Franco. Cuando Sainz Rodríguez y Gil Robles le preguntaron si debían continuar las conversaciones con la izquierda, se reafirmó en «seguir el camino trazado», y les prometió «no adquirir el más ligero compromiso sin contar con ellos». ${ }^{43}$ En enero de 1949, Gil Robles y Sainz Rodríguez, admirados de que los socialistas siguiesen defendiendo a D. Juan, reanudaron las conversaciones ${ }^{44}$. A Prieto no le quedaba más

41 FO371-73359, Z8130, 6-10-48; AD/MAE, Z,44, 6-10-48 y José M. ${ }^{\text {a }}$ del Valle, Las instituciones de la República española en el exilio, Ruedo Ibérico, París, 1976, pp.285-286.

42 Conversación de D. Juan con un asistente especial de la embajada USA en Lisboa el 2-11-48. Para D. Juan el acuerdo con los socialistas era más un conjunto de principios políticos que un acuerdo operativo entre partidos, y que por eso no requería firmas, FRUS, Vol. III, 1948, 852.00/11-1048, p.1062.

43 Gil Robles, La monarquía, (anotación de 11-1-49), p. 289, Citado en: Santos Juliá, Los socialistas en la política española, 1879-1982, Taurus, Madrid, 1997, p. 317.

44 Santos Juliá, op. cit., p. 317. 
remedio que seguir confiando en la única salida que le quedaba y donde había puesto todo su empeño: el pacto con los monárquicos.

\section{NUEVO GOBIERNO DE PARTIDOS REPUBLICANOS}

El 8 de agosto de 1947 se había formado un nuevo gobierno presidido por Álvaro de Albornoz, con representantes de partidos republicanos, tras la dimisión de Rodolfo Llopis. La ratificación de la resolución de 1946 en la Asamblea de la ONU de noviembre de1947 dio un respiro al nuevo gobierno y de paso una excusa para reafirmar su autoridad y defender la existencia de las instituciones de las que formaba parte. Tras su regreso de Nueva York, Albornoz arremetió contra la alternativa que desplazaba al gobierno republicano e incluía a los monárquicos en un frente antifranquista. ${ }^{45}$ Decía haber advertido la desilusión entre los emigrados viendo a muchos de ellos «volviendo desde la seducción de un espejismo». Albornoz achacaba el no haber conseguido una resolución más favorable para la causa republicana, además de a la grave situación internacional, a «nuestras divisiones» y a la «multiplicidad de actuaciones» que habían disminuido la autoridad del gobierno en los momentos que más lo necesitaba. Según el presidente, el derecho avalaba a las instituciones republicanas, ahí estaban los once estados europeos y americanos que habían reconocido su legitimidad: "Nada puede sustituir a las Instituciones, no ya con ventaja, pero ni siquiera igualándolas en eficacia». Mientras tanto, la convocatoria de las Cortes para el 25 de noviembre se aplazó aduciendo motivos ajenos a la voluntad del Gobierno. Albornoz se comprometió a convocarlas en cuanto se pudiera. ${ }^{46}$

Albornoz se encontraba con la imposibilidad de ir más allá de las meras reivindicaciones y los reconocimientos internacionales meramente retóricos y finalmente presentó su dimisión a Diego Martínez Barrio. De los tres gobiernos en el exilio habidos desde septiembre de 1945, éste había sido el más largo, aunque eso no quería decir mucho. En realidad había sido un gobierno poco representativo compuesto por ministros de partidos con apellido republicano, y sin la presencia de partidos izquierdistas.

El 6 de diciembre, el presidente de la República, Diego Martínez Barrio, volvió a encomendar a Albornoz la formación del gobierno que sería presentado el 16 de febrero de 1949. Mientras, la oposición interior se desenvolvía en un país dividido y aislado que vivía una posguerra muy dura donde la mayoría de la gente deseaba, sobre todo, vivir en paz. ${ }^{47}$

45 Declaraciones de Álvaro de Albornoz en París, 16-12-47, ARE 658.1., 2.1.1., 17-12-47.

46 ARE, 658.1, 2.1.1., 17-12-47.

47 «La oposición española ha perdido el barco. En 1945 los dictadores eran impopulares. Los aliados habían ganado una guerra diseñada para acabar con ellos. La oposición nunca logró unirse. El orgullo español también ayudó a este extremo. La gente decía que no podían hacer nada contra el régimen sin apoyo exterior. Cuando obtuvieron fuera dicho apoyo y Franco fue condenado (las recomendaciones de 
Cada vez más políticos y miembros del gobierno creían necesario realizar profundos cambios en la acción institucional. Incluso el propio Albornoz llego a decir que las instituciones republicanas estaban dispuestas a hacer sacrificios, «si hay posibilidades de una solución transitoria, de una evolución pacífica hacia un régimen democrático, (...)».48

\section{LAS EXPECTATIVAS SE DISIPAN}

La famosa carta del secretario de estado norteamericano, Dean Acheson, al jefe de Comité de relaciones internacionales del Senado, y senador demócrata por Texas, Tom Connally, ${ }^{49}$ tuvo una gran repercusión, tanto entre la oposición republicana, como en el seno del régimen franquista. Contó con la aprobación del presidente estadounidense, Harry Truman, y fue publicada a indicación suya, como supo después el embajador español en Washington, José Félix de Lequerica, tras contárselo el propio Truman a varios congresistas. ${ }^{50}$ Acheson sugería la modificación de la resolución de la ONU de diciembre de 1946 para poder enviar de nuevo embajadores a Madrid. El régimen español interpretó la carta como una confirmación de que había valido la pena la espera, de que Franco tenía razón. ${ }^{51}$

Para el gobierno republicano, sin embargo, aquello era un duro golpe, como demuestra la declaración que Albornoz hizo el 20 de enero de 1950, dedicada íntegramente a la carta de Acheson, ${ }^{52}$ en la que criticaba cada uno de sus argumentos y pedía la rectificación de la política norteamericana.

Estados Unidos con su equivocada política - y no lo digo yo- lo dice el eminente escritor norteamericano Walter Lipmann, ha sembrado la simiente del comunismo en China; Estados Unidos, con esta política, que tanto deploramos, esta sembrando la simiente del comunismo en España.

En noviembre de 1950, la Asamblea General de la ONU derogó el acuerdo de 1946 con el apoyo de Estados Unidos, la abstención de Gran Bretaña y Francia, y el voto en contra de la Unión Soviética. Caía el gran «cartel publicitario» que aún les quedaba en el mundo a la oposición antifranquista y la República en el exilio.

la ONU de diciembre de 1946), la misma gente protestaba porque aquello era un insulto al orgullo nacional, una interferencia exterior en los asuntos nacionales». C. L. Sulzberger, «Franco opposition believed smashed», New York Times, 30-11-48, AD/MAE, Z, 81, 2-12-48.

48 Política, 27-8-49, citado por J. M. DEL VALLE, op. cit., p. 302.

49 Acheson a Connally, FRUS, Vol. III, 1950, 611.52/1-1650, pp. 1549-1555. El texto del documento, que fue aprobado por los departamentos de Defensa y Estado, y por el presidente Truman, que añadió leves retoques, fue dado a conocer a la prensa el 19 de enero; A este respecto, ver también: FO37189496, 8-2-50, y AD/MAE, Z, 159, 19-1-50.

50 Antonio Marquina Barrio, España en la política de seguridad occidental, 1939-1986, Ediciones Ejército, Madrid, 1986, p. 319.

51 Paul Preston, Franco, «Caudillo de España», Grijalbo, Barcelona, 1994, p. 736.

52 Declaraciones del Presidente del gobierno de la República española, D. Alvaro de Albornoz, en la conferencia de prensa del 20 de enero de 1950, en la embajada española en México, el día después de que la declaración de Acheson fuese dada a conocer, ARE, 437.5., 1.3.2., 20-1-50. 
La resolución de la ONU de noviembre de 1950 sería el batacazo final de un gobierno que se había mantenido, más por la inercia de la necesidad de su propia existencia, que por lo imprescindible de su labor. El 2 de diciembre de 1950, Álvaro de Albornoz dimitió apostando por la continuidad política y solicitando que el nuevo gobierno tuviese una composición análoga al dimisionario. ${ }^{53}$ Diego Martínez Barrio, no aceptó la dimisión, y el día 6 encargó a Albornoz la formación de un nuevo gobierno.

El 10 de julio de 1951, Don Juan escribió a Franco apremiándole a restaurar la monarquía. Utilizaba argumentos «razonables», recordándole su común identificación con el «Movimiento Nacional». Le avisaba de lo que sucedería si no daba pasos positivos en la evolución del régimen. Según los norteamericanos, la decisión de enviar la misiva se debió a la presión ejercida por los asesores del Pretendiente en Estoril, pero también habría influido el deseo de Don Juan de atajar los rumores que se extendieron en junio, parece ser que originados en El Pardo, que hablaban de una posible abdicación en su hijo Don Juan Carlos el 18 de julio. Franco llegó a decir en un consejo de ministros que el Pretendiente era inaceptable y que el 18 de julio designaría sucesor a Don Juan Carlos. No lo hizo, era un castigo excesivo. ${ }^{54}$ Indalecio Prieto criticó su actitud sumisa en un artículo que titulaba: «El príncipe mendicante». ${ }^{55}$ Todavía en julio de 1950 el IV Congreso del PSOE ratificó el pacto con los monárquicos. Don Juan y sus consejeros cercanos se habían aplicado en mantener una buena relación con el más importante partido republicano para asegurarse una transición tranquila. En una carta a Franco el 10 de julio, el propio Don Juan reconocía esta estrategia.

Esto no quiere decir que yo haya ignorado - sin creer conveniente prohibirlaslas actividades de elementos monárquicos que bajo su exclusiva responsabilidad han procurado, pensando en el día de mañana, neutralizar las posible tendencia revolucionaria de sectores obreros españoles anticomunistas, encauzándolos por rumbos de cooperación social y patriótica ${ }^{56}$.

El Partido Socialista por su parte, había tratado de posibilitar una transición donde pudiese estar presente la izquierda. Después de que la ONU dejara sin efecto la resolución de 1946 Prieto, cansado y harto, decidió que había llegado el momento de abandonar Francia y volver a México, pues «ya no había más que hacer». .57

EI PSOE celebró un Congreso extraordinario en Toulouse el 31 de marzo y el 1 de abril de 1951, donde se aprobó continuar la línea seguida hasta entonces, es decir, la de Prieto. La carta de Don Juan a Franco terminó con la paciencia de los socialistas. El 5 de noviembre de ese año, la ejecutiva retiró a sus representantes

53 Carta de dimisión de Albornoz al presidente Diego Martínez Barrio, ARE, 23.4., 1.12.4., 2-12-50.

54 Embajada USA en Madrid al Departamento de Estado, FRUS, Vol. IV, 1951, 752.00/9-551, p. 863.

55 Artículo de Indalecio Prieto en El Socialista, 25-10-51, ARE, 236.1.,1.12.4., 25-10-51.

56 Citado en parte por Prieto en un artículo publicado en El Socialista, ARE, 236.1., 1.12.4., 25-10-51.

57 The Shape of Things, artículo publicado en The Nation, 25-11-50, AD/MAE, Z, 160, 25-11-50. 
en el Comité de enlace: Trifón Gómez y Rodolfo Llopis, sustituto éste de Prieto; y en agosto de 1952, el V Congreso del PSOE declaraba cancelado el acuerdo de 1948.

Tras la resolución de la ONU y el acercamiento norteamericano a Franco la desilusión, sin embargo, abarcaba a todos los grupos, incluso al Partido Comunista. Albornoz dimitió definitivamente el 8 de julio de 1951 y el 13 de agosto, Felix Gordón Ordás fue encargado por el presidente de la República para sustituirle. El nuevo Ejecutivo no quedó configurado hasta el día 17 de noviembre, con miembros de partidos republicanos liberados de la disciplina de grupo..$^{58}$ Su programa defendía la legitimidad de las Instituciones republicanas, por fidelidad histórica, y también porque si no, no podría denominarse gobierno republicano. ${ }^{59}$

A principios de 1952, México, el principal valedor del gobierno en el exilio, negó su permiso a una reunión de las Cortes republicanas. Según Gordón Ordás, la negativa venía de la Presidencia de la República de México, pero en ella habrían influido las presiones de Estados Unidos. El chasco llevó a Martínez Barrio a reconocer que nadie, salvo Gordón Ordás y él mismo, deseaban la reunión de las Cortes, por lo que recomendó al presidente del Gobierno que regresara a París cuanto antes. ${ }^{60}$

Muchos exiliados no entendían ya el empeño en seguir manteniendo un gobierno republicano en el exilio. Luis Araquistain era uno de ellos, había sido siempre muy crítico con el gobierno en el exilio, por eso, cuando Gordón Ordás le invitó a una reunión de diputados en París, el 29 de enero de 1952, disculpó su asistencia y le hizo alguna sugerencia:

¿No le parece a Vd. Sr. Presidente, que ya es hora de dar por terminado este triste espectáculo internacional, triste más por ridículo que por macabro, y enterrar definitiva y solemnemente nuestra República? Yo creo que si.

(...)Fuera de España, lo único que hacemos es irnos muriendo todos poco a poco, lo cual es otro modo de liquidar también a la postre, por consunción personal, las Instituciones republicanas. Esa forma de resistencia podrá ser una especie de romanticismo mitigado, con pan y sin piras colectivas; pero no es una política. Hacer política es construir dentro de los posible, en cada momento, para la vida y no para la muerte ${ }^{61}$.

Para Álvaro de Albornoz: «El gobierno republicano español, sin recursos materiales, abandonado por los que más deberían sostenerlo, es sólo una fuerza moral, pero es, nadie puede dudarlo, una gran fuerza moral». ${ }^{62}$ Tenía razón, había

58 José M. a DEL VALLE, Op. cit., p. 320.

59 Declaración ministerial del nuevo gobierno, AD/MAE, Z, 134, 22-11-51.

60 Carta de Martínez Barrio a Gordón Ordás, ARE, 215.1., 4.2.1., 21-2-52.

61 Carta de Luis Araquistain a Félix Gordón Ordás, ARE, 733.4., 1.3.2., 24-1-52.

62 Declaraciones de A. de Albornoz tras la aprobación de un crédito a España por el senado norteamericano, ARE, 735.1., 1.13.2., (Sin fecha, pero con toda probabilidad de agosto de 1950). Este papel de fuerza moral representado por el gobierno republicano en el exilio, es también destacado por JAVIER 
sido una gran fuerza moral, a veces cercana a lo simbólico, que quizás era lo único a que podía aspirar en el difícil escenario en que le tocó desenvolverse y con lo veteranos actores que la representaron. En sus memorias, cuando Diego Martínez Barrio reflexionaba acerca del significado del gobierno en el exilio: «...las circunstancias nos han reducido a un mero símbolo". ${ }^{63}$ Pero, con toda seguridad, la mayoría de los españoles habían confiado en que iba a ser mucho más que eso.

TUSELl y Alicia ALted en su artículo: The Government of the Spanish Republic in Exile, (1939-1977), en: Governments-in-exile in Contemporary Worlds Politics, Edited by Yossi Sahin, Routledge, New York and London, 1992, p. 161.

63 Diego Martínez Barrio, (1945-1955), Diarios, manuscrito en el Archivo Histórico Nacional de Madrid, citado en: María GloriA NúÑez PÉrez, Diego Martínez Barrio: una vida en defensa de los ideales e instituciones republicanos, Cuadernos Republicanos, n. ${ }^{\circ}$ 19, CIERE, Madrid, julio de 1994, p. 215. 